\title{
Factors influencing Canadian family practice anesthetists' retention: a cross-sectional survey
}

\author{
Joel Buhiire, MD, CCFP • Adam Mildenberger, MD, CCFP $\cdot$ Rebecca Epp, MD, \\ CCFP $($ FPA) $\cdot$ Jagmeet Bajwa, MSc $\cdot$ Murray Dease, MD, \\ FRCPC $\cdot$ Jennifer O'Brien, PhD
}

Received: 26 June 2019/Revised: 17 September 2019/Accepted: 17 March 2020/Published online: 6 April 2020

(c) Canadian Anesthesiologists' Society 2020

\section{To the Editor,}

Family practice anesthetists (FPAs) are essential to delivery of rural medical services, including surgery, obstetrics, and critical care. ${ }^{1}$ Family practice anesthetists training demands a significant investment of resources ${ }^{2}$; therefore, it is alarming that their average career lifespan is fewer than ten years. ${ }^{3}$ Determining factors affecting FPA retention may help to address the increasing shortage of anesthesia providers. The purpose of this survey of FPAs was to describe characteristics of their training and practice, reasons why they leave practice, and suggestions to improve their retention.

Following research ethics approval (March 2018), we surveyed Canadian FPAs using the online FluidSurveys tool (Appendix). Survey questions were developed using literature review, focused discussion, and pre-testing on two former FPAs (now Royal College of Physicians and Surgeons of Canada accredited (FRCPC) anesthesiologists), a FRCPC anesthesiologist, and one FPA. ${ }^{4}$ Snowball sampling began with two authors (R.E., M.D.) who have completed FPA training and encouraged FPA colleagues to circulate the survey link. FPA program assistants across Canada also distributed the invitation to FPA contacts. Recipients were informed that responses would be used for research and that survey completion implied consent.

One hundred and sixty-four Canadian FPAs responded to the survey (of an estimated 500 practicing in Canada). ${ }^{1}$ Practice location was distributed across Canada, with

J. Buhiire, MD, CCFP · A. Mildenberger, MD, CCFP · R. Epp, MD, CCFP (FPA) - J. Bajwa, MSc - M. Dease, MD, FRCPC . J. O'Brien, PhD ( $\square)$

Department of Anesthesiology, Perioperative Medicine and Pain Management, University of SK, Saskatoon, Canada

e-mail: Jennifer.OBrien@usask.ca representation from Yukon/Northwest Territories/Nunavut (8/140, 6\%), British Columbia (32/140, 23\%), Alberta (20/ $140,14 \%)$, Saskatchewan (5/140, 4\%), Manitoba (6/140, $4 \%$, and Ontario/Quebec/Maritime provinces (69/140, $49 \%)$. Respondents were primarily male (124/164, 76\%), aged 30-49 yr (96/162, 59\%), currently practicing as an FPA $(142 / 164,87 \%)$, practiced in communities with 5,00019,000 residents $(87 / 144,60 \%)$, and worked with 1-3 FPA colleagues in their community $(73 / 158,46 \%)$. Demographic characteristics are outlined in the Table.

Of the FPAs that indicated they were no longer practicing, the most common reason provided was moving to a new community $(6 / 17,35 \%)$, followed by personal/family reasons $(4 / 17,24 \%)$. Less common reasons included retirement $(2 / 17,12 \%)$, burdensome call $(2 / 17,12 \%)$, and feeling overwhelmed by the responsibilities of an FPA (2/17, $12 \%)$. Of note, no respondents indicated they discontinued practice as an FPA because of financial reasons (0/17).

When asked what would help support FPA providers to continue FPA practice, respondents indicated opportunities to do refresher time in a centre with a larger volume of complex cases ( $n=108 / 161,67 \%)$, an FPA locums list (90/ $161,56 \%$ ), support from hospitals and health regions in recruitment $(84 / 161,52 \%)$, formal mentoring program with FRCPC anesthesiologists (69/161, 43\%), financial incentives (60/161, 37\%), and a formal mentoring program with an FPA $(49 / 161,30 \%)$ would be helpful.

Our findings contribute to understanding the characteristics of Canadian FPAs and the reasons they discontinue FPA practice. The most common reason provided for ending FPA practice was moving to another community, which may reflect the larger problem of retaining family physicians in rural areas. ${ }^{5}$ Future research could investigate the reasons FPAs move away from their communities. Although no respondents cited financial 
Table Characteristics of Canadian FPA respondents

\begin{tabular}{|c|c|c|c|}
\hline & All respondents & Practicing FPAs & Non-practicing FPAs \\
\hline \multicolumn{4}{|l|}{ Gender } \\
\hline Male & $124 / 163(76 \%)$ & $107 / 142(75 \%)$ & $17 / 21(81 \%)$ \\
\hline Female & $39 / 163(24 \%)$ & $35 / 142(25 \%)$ & $4 / 21(19 \%)$ \\
\hline \multicolumn{4}{|l|}{ Age (yr) } \\
\hline $20-29$ & $7 / 162(4 \%)$ & $4 / 142(3 \%)$ & $3 / 20(15 \%)$ \\
\hline $30-39$ & $49 / 162(30 \%)$ & $42 / 142(30 \%)$ & $7 / 20(35 \%)$ \\
\hline $40-49$ & $47 / 162(29 \%)$ & $42 / 142(30 \%)$ & $5 / 20(25 \%)$ \\
\hline $50-59$ & $35 / 162(22 \%)$ & $33 / 142(23 \%)$ & $2 / 20(10 \%)$ \\
\hline$>60$ & $24 / 162(15 \%)$ & $21 / 142(15 \%)$ & $3 / 20(15 \%)$ \\
\hline \multicolumn{4}{|l|}{ Length of practice as an FPA (yr) } \\
\hline $1-5$ & 48/161 (30\%) & $37 / 142(26 \%)$ & $11 / 17(65 \%)$ \\
\hline $6-10$ & $25 / 161(16 \%)$ & $24 / 142(17 \%)$ & $1 / 17(6 \%)$ \\
\hline$>10$ & $86 / 161(53 \%)$ & $81 / 142(57 \%)$ & $5 / 17(29 \%)$ \\
\hline Transferred directly into 5-yr anesthesia residency & $2 / 161(1 \%)$ & $0 / 142(0 \%)$ & $0 / 17(0 \%)$ \\
\hline \multicolumn{4}{|l|}{ Community size in which they practice } \\
\hline$<5,000$ & $10 / 144(7 \%)$ & $10 / 142(7 \%)$ & $0 / 2(0 \%)$ \\
\hline $5,000-19,999$ & $87 / 144(60 \%)$ & $87 / 142(61 \%)$ & $0 / 2(0 \%)$ \\
\hline $20,000-49,999$ & $40 / 144(28 \%)$ & $39 / 142(27 \%)$ & $1 / 2(50 \%)$ \\
\hline$>50,000$ & $7 / 144(5 \%)$ & $6 / 142(4 \%)$ & $1 / 2(50 \%)$ \\
\hline \multicolumn{4}{|l|}{ Number of FPA colleagues } \\
\hline 0 & $11 / 158(7 \%)$ & $10 / 142(7 \%)$ & $1 / 15(7 \%)$ \\
\hline 1-3 FPA & $73 / 158(46 \%)$ & $65 / 142(46 \%)$ & $7 / 15(47 \%)$ \\
\hline$>4$ FPA & $36 / 158(23 \%)$ & $33 / 142(23 \%)$ & $3 / 15(20 \%)$ \\
\hline FPA and FRCPC & $38 / 158(24 \%)$ & $34 / 142(24 \%)$ & $4 / 15(27 \%)$ \\
\hline \multicolumn{4}{|l|}{ FPA training location } \\
\hline British Columbia & $18 / 163(11 \%)$ & $14 / 142(10 \%)$ & 4/17 (24\%) \\
\hline Alberta & $25 / 163(15 \%)$ & $20 / 142(14 \%)$ & $4 / 17(24 \%)$ \\
\hline Saskatchewan/Manitoba & $20 / 163(12 \%)$ & $15 / 142(11 \%)$ & $4 / 17(24 \%)$ \\
\hline Ontario & $70 / 163(43 \%)$ & $66 / 142(46 \%)$ & $4 / 17(24 \%)$ \\
\hline Other & $30 / 163(18 \%)$ & $27 / 142(19 \%)$ & $1 / 17(6 \%)$ \\
\hline \multicolumn{4}{|l|}{ Had exposure to FPA practice } \\
\hline During medical school & $157 / 164(98 \%)$ & $140 / 142(99 \%)$ & $17 / 17(100 \%)$ \\
\hline During family medicine residency & $97 / 164(59 \%)$ & $85 / 142(60 \%)$ & $12 / 17(71 \%)$ \\
\hline While working as family physician & $43 / 164(26 \%)$ & $38 / 142(27 \%)$ & $5 / 17(29 \%)$ \\
\hline During FPA residency & $82 / 164(50 \%)$ & $74 / 142(52 \%)$ & $8 / 17(47 \%)$ \\
\hline
\end{tabular}

FPA = family practice anesthetists.

reasons for discontinuing FPA work, 37\% of respondents overall indicated that financial incentives might support continued practice as an FPA. These findings suggest that, while financial compensation may sweeten the deal, it may not alter fundamental concerns of excess call, isolation, or address personal or family-related issues. Further research could explore what kinds of financial incentives might help, if FPAs think they are fairly compensated, and whether financial incentives alone would retain FPAs in practice. Refresher time for skill enhancement would be very welcome, but FPAs struggle to find locums or colleagues to cover clinical duties while away. Professional bodies, specialist anesthesiologists, and hospital leadership should prioritize the creation of a formal refresher program in addition to addressing human resource issues such as a list of locums and recruitment of new FPAs to rural communities.

\section{Conflicts of interest None.}

\section{Funding statement None.}

Editorial responsibility This submission was handled by Dr. Gregory L. Bryson, Deputy Editor-in-Chief, Canadian Journal of Anesthesia. 


\title{
Appendix: Survey of Canadian FPA graduates
}

\author{
What is your gender? \\ ○ Male \\ ○ Female \\ O Other
}

How old are you?
○ $20-29$
○ $\quad 30-39$
○ $40-49$
○ $50-59$
A $>60$

At the time of your FPA training, what was your family status?
○ Single
○ Single parent
○ Married/common-law
O Married/common-law, with children

What was the size of the community you grew up in?
○ $<5,000$
○ $5,000-10,000$
○ $10,000-20,000$
○ $>20,000$

In which country did you complete your family medicine program?

O Canada

International
Did you complete an urban or rural family medicine program?
O Urban
○ Rural
Did you have exposure to FPA practice? (Select all that apply.)
$\square \quad$ During medical school
$\square$ During family medicine residency
$\square$ While working as a family physician
$\square$ During FPA residency
$\square$ Other, please specify:

Were you in family practice prior to starting your FPA residency?

○ Yes

O No

Why did you choose to do FPA training? (Select all that apply.)

$\square$ I always planned on becoming an FPA

$\square$ I discovered full-time family practice was not for me

$\square \quad$ A community I was moving to needed another anesthesia provider

$\square \quad$ I wanted more training before going into rural family practice 
I hoped to continue into FRCPC anesthesia

$\square$ Other, please specify...

How many years were you in family practice prior to training as an FPA?

$\bigcirc<5$ years

○ 6-10 years

○ 11-15 years

○ >15 years

Why did you go back to train as an FPA? (Select all that apply.)

$\square \quad$ I needed a change in practice

$\square$ Personal/family reasons

$\square \quad$ Need for another anesthesia provider in the community

$\square \quad$ I wanted more critical care skills

$\square$ Other, please specify:

Were you committed to a community to provide anesthesia care prior to starting your FPA year?

Y Yes

○ No

Did you have family medicine requirements as a part of your FPA curriculum? (I.e., family medicine clinics/mandatory shifts in rural community [moonlighting not applicable])

○ Yes

○ No

What type of family medicine requirement was it? (Select all that apply)

$\square$ Longitudinal days in family medicine

$\square \quad$ Block of family practice anesthesia

$\square \quad$ Family medicine block

$\square$ Other, please specify:

Did you complete FPA training in a centre with a specialist anesthesia program?

O Yes

○ No

How long did you/have you worked as an FPA?

O Transferred directly into 5-year anesthesia residency

○ $1-5$ years

○ 6-10 years

○ $>10$ years

Are you currently working as an FPA?

O Yes

O No

Did you/do you work as an FPA in a setting with anesthesia colleagues?

○ 0 colleagues

○ 1-3 FPA colleagues

○ $>4$ FPA colleagues

FPA and FRCPC colleagues 
What was the reason you completed your career as an FPA? (Select all that apply)

$\square$ Retired

$\square \quad$ The call was burdensome

$\square$ The responsibility was overwhelming

$\square$ Personal/family reasons

$\square \quad$ I moved to another community and work as an FPA was not available

$\square \quad$ Financial reasons

$\square$ Other, please specify:

Where do you primarily practice?
O Alberta
○ British Columbia
O Manitoba
○ New Brunswick
○ Newfoundland and Labrador
○ Northwest Territories
○ Nova Scotia
○ Nunavut
○ Ontario
O Prince Edward Island
○ Quebec
○ Saskatchewan
○ Yukon
Other, please specify:

How big is the community you practice in?
O $<5,000$
○ $5,000-19,999$
○ $20,000-49,999$
○ $>50,000$

What is the estimated catchment area for your health facility?
O $<20,000$
○ $20,000-49,999$
○ $50,000-100,000$
○ $>100,000$

Why did you go on to complete the FRCPC anesthesia residency? (Select all that apply.)

$\square$ My intention was to go directly into the five-year program upon entry into the FPA year

$\square \quad$ I was encouraged to go on to a Royal College program by my residency program director or preceptors in the FPA program

$\square$ My plans evolved during my FPA year

$\square$ Family/personal reasons

$\square$ Other, please specify: 
What are things you feel would be helpful to support FPA providers to continue in FPA practice? (Select all that apply)

$\square \quad$ List of possible FPA locums

$\square$ Regular opportunities to do refresher weeks in higher volume centres

$\square$ Formal mentoring program with anesthesiologist

$\square$ Formal mentoring program with an FPA

$\square$ Financial incentives

$\square$ Support from hospitals and health regions in recruitment

$\square$ Other, please specify:

If you would be willing to engage in further discussions regarding FPA retention, please follow this link to enter your phone number and/or email address.

O Phone number:

O Email:

\section{Any further comments regarding FPA retention.}

$\mathrm{FPA}=$ family practice anesthetists.

\section{References}

1. Orser BA, Wilson RC, Rotstein AJ, et al. Improving access to safe anesthetic care in rural and remote communities in affluent countries. Anesth Analg 2019; 129: 294-300.

2. Society of Rural Physicians of Canada. Joint position paper on training for rural family physicians in anesthesia. Can J Rural Med 2001; 6: Insert 1-19.

3. Donen N. Family practice anesthesia - a follow-up. Can J Anaesth 1995; 42: A49 (abstract).
4. Burns KE, Duffett $M$, Kho ME, et al. A guide for the design and conduct of self-administered surveys of clinicians. CMAJ 2008; 179: $245-52$.

5. Fleming $P$, Sinnot $M L$. Rural physician supply and retention: factors in the Canadian context. Can J Rural Med 2018; 23: 15-20.

Publisher's Note Springer Nature remains neutral with regard to jurisdictional claims in published maps and institutional affiliations. 